\title{
Experiências de mulheres em situação de violência em busca de atenção no setor saúde e na rede intersetorial
}

Joannie dos Santos Fachinelli Soares ${ }^{(a)}$

Marta Julia Marques Lopes ${ }^{(b)}$

Soares JSF, Lopes MJM. Experiences of women in situation of violence seeking care in the health sector and in the intersectoral network. Interface (Botucatu). 2018;

22(66):789-800.

The objective of this study was to analyze the experiences of women in situation of violence seeking care in the health sector and in the intersectoral network, using a qualitative approach. The participants were 14 women assisted in a Women's Care Reference Center due to situations of violence in intimate relationships. In-depth interviews and documentary research were conducted on the service charts. Content analysis evidenced inappropriate practices on the part of the professionals and the organization, and a structure with several services to assist these women. It is necessary to establish an appropriate coordination of the intersectoral network to meet both the practical aspects of coping with violence and the care of physical harm to these population, ensuring their rights and safety, and offering support to the suffering experienced.

Keywords: Violence against women. Health care. Intersectoral collaboration.
O estudo teve por objetivo analisar as experiências de mulheres em situação de violência em busca de atenção no setor da saúde e na rede intersetorial. Utilizou-se abordagem qualitativa. As participantes foram 14 mulheres atendidas em um Centro de Referência de Atendimento à Mulher em decorrência de situações de violência nas relações íntimas. Foram realizadas entrevistas em profundidade e pesquisa documental nos formulários de atendimentos. A análise de conteúdo constatou inadequação das práticas profissionais e da organização e estrutura de muitos serviços para acolher essas mulheres. Destaca-se a necessidade de estabelecer adequada articulação da rede intersetorial para tanto atender os aspectos práticos do enfrentamento da violência, tais como a atenção aos danos físicos e a garantia dos direitos e da segurança, quanto para oferecer apoio ao sofrimento decorrente.

Palavras-chave: Violência contra a mulher. Atenção à saúde. Intersetorialidade. (a) Escola de Saúde, Universidade do Vale do Rio dos Sinos. Avenida Dr. Nilo Peçanha, 1.600, Bairro Boa Vista. Porto Alegre, RS, Brasil. 91330-002.joanniefs@ unisinos.br

(b) Programa de Pós-Graduação em Desenvolvimento Rural, Faculdade de Ciências Econômicas, Universidade Federal do Rio Grande do Sul. Porto Alegre, RS, Brasil. marta@enf.ufrgs.br 


\section{Introdução}

A violência contra as mulheres é um problema de grande magnitude que, além de violação de direitos humanos, impacta profundamente nas situações de saúde por ser fonte de grande sofrimento para as mulheres ${ }^{1}$. Portanto, torna-se necessário o acolhimento dos eventos de violência pelo setor da Saúde e pela rede intersetorial e a responsabilização profissional com as usuárias nessa situação.

No que se refere à rede intersetorial, a Lei Maria da Penha (Lei no 11.340/2006) ${ }^{2}$, que criou mecanismos para coibir a violência doméstica e familiar contra a mulher, determina que os atendimentos às mulheres devem ser realizados de forma articulada na rede de atenção. Entretanto, ainda são necessários avanços para que as mulheres recebam atendimentos humanizados e resolutivos. Constatam-se dificuldades de articulação entre os serviços que integram a rede de atenção para o enfrentamento da violência contra a mulher. Além disso, na dimensão profissional, prevalece o despreparo para o reconhecimento da violência, para o acolhimento da mulher e até mesmo para o processo de encaminhamento na rede, decorrente do desconhecimento dos serviços e de suas atribuições ${ }^{3}$.

Mulheres em situação de violência necessitam de ajuda para superar as barreiras sociais, culturais, econômicas e políticas que as impedem de procurar ajuda. Dessa forma, o enfrentamento das situações de violência requer ações em múltiplas dimensões, que podem incluir tanto ajudar as mulheres a reconhecerem que a violência não é aceitável e que tem consequências desfavoráveis para ela e seus filhos - fornecendo apoio emocional e respeitando a autonomia de cada mulher no processo de tomada de decisão - quanto ações práticas, como prover auxílio para alcançar a independência financeira ${ }^{4}$.

Na perspectiva da integralidade da atenção, Costa e Lopes $^{5}$ ressaltam a importância de dispositivos relacionais, como acolhimento, vínculo e diálogo. O acolhimento envolve compreensão e respeito às situações vivenciadas pelas mulheres. A ação de ouvir as inquietações das usuárias dos serviços, de modo interessado e acolhedor, favorece a construção do vínculo que encoraja o relato do sofrimento e possibilita a detecção da violência. Além disso, a dimensão da orientação coloca-se enquanto estratégia importante para mediar as interlocuções entre os sujeitos e é fundamental para nortear, empoderar e fortalecer as mulheres para o enfrentamento das situações de violência.

Considera-se a violência contra a mulher como um problema complexo, com causalidade multifatorial e com consequências que se estendem muito além das lesões físicas, e que, portanto, necessita de intervenções para além da identificação e dos encaminhamentos. Assim, este estudo teve por objetivo analisar as experiências de mulheres em situação de violência em busca de atenção na saúde e na rede intersetorial.

\section{Método}

Trata-se de estudo com abordagem qualitativa, que possibilita a apreensão dos aspectos subjetivos para a compreensão e interpretação das experiências pessoais de quem fornece a informação, permitindo analisar as histórias sociais sob a ótica dos atores ${ }^{6}$.

As participantes do estudo são 14 mulheres que foram atendidas, em decorrência de situações de violência nas relações íntimas, em um Centro de Referência de Atendimento à Mulher Vítima de Violência (Cram), localizado em uma capital do Brasil. Para acesso ao serviço, foi realizado contato prévio com a coordenação do Cram, que concedeu autorização para o desenvolvimento do estudo nesse local. A pesquisadora contou com o auxílio da equipe do serviço para o contato e convite às mulheres para a realização das entrevistas. Foi explicado a todas as mulheres convidadas que a pesquisadora/entrevistadora não era funcionária da equipe e que seu atendimento no local não seria prejudicado por sua recusa ou participação no estudo. Teve-se o cuidado de não incluir aquelas que os profissionais da equipe consideravam sem condições emocionais para a entrevista por se mostrarem ainda muito fragilizadas. 
A geração dos dados foi realizada por meio de pesquisa documental nos formulários de atendimentos do Cram e entrevistas em profundidade, no período de agosto de 2014 a julho de 2015. Durante as entrevistas, as participantes foram estimuladas a falar sobre as suas experiências na busca de atenção em relação às situações de violência vivenciadas. A pesquisa nos formulários permitiu complementar informações sociodemográficas e dos atendimentos das mulheres referentes a essas experiências.

A análise dos dados buscou preservar as singularidades de cada trajetória e, ao mesmo tempo, identificar as experiências comuns que permitissem inferência para a compreensão dos seus significados. Para tanto, empregaram-se as etapas da análise de conteúdo preconizadas por Bardin ${ }^{7}$. Os resultados são apresentados tematizando os setores e/ou serviços da rede utilizados pelas participantes do estudo.

No que se refere à análise para o setor saúde, utilizou como categoria analítica o referencial de Raynaut ${ }^{8}$ sobre as dimensões de materialidade e imaterialidade, que são consideradas pertinentes sob a ótica da integralidade à saúde. De acordo com o autor ${ }^{8}$, a articulação entre os fatos materiais e imateriais como inter-relacionais e a complexidade desses dois universos ajudam a entender a realidade híbrida das interações humanas. Nessa perspectiva, a materialidade se expressa no físico, no biológico e nas condições de vida, enquanto a imaterialidade envolve as relações sociais, os saberes e a cultura (representações, valores e normas).

O desenvolvimento da pesquisa foi realizado respeitando as diretrizes e normas referentes à pesquisa envolvendo seres humanos, expressas na Resolução n 466/2012, do Conselho Nacional de Saúde. Todas as participantes do estudo assinaram o Termo de Consentimento Livre e Esclarecido. Para garantir o anonimato, conforme os preceitos éticos adotados, todas as participantes estão identificadas com nomes fictícios. A pesquisa foi aprovada pelo Comitê de Ética em Pesquisa.

\section{Resultados e discussão}

Para possibilitar melhor compreensão sobre os resultados do estudo, apresentam-se, incialmente, algumas informações para a caracterização das participantes. Conforme pode ser observado no Quadro 1, as idades variaram de 25 a 70 anos, sendo que cinco mulheres tinham até 35 anos, sete estavam na faixa etária de 40 a 60 anos e duas tinham mais de 60 anos de idade. Autodeclararam-se brancas 11 das entrevistadas, duas como pardas e uma como negra. Quanto à escolaridade, cinco das participantes estudaram até o ensino fundamental, cinco até o ensino médio e quatro possuíam ensino superior. Entre as entrevistadas, nove possuíam renda própria. As situações de violência foram provocadas por companheiros (seis) e ex-companheiros (oito). Para quase todas elas, o tempo de relacionamento com o agressor foi longo, com média de 25 anos entre as 14 participantes.

Quadro 1. Caracterização das participantes do estudo

\begin{tabular}{|l|l|l|l|c|l|l|}
\hline Codinome & Idade & Raça/cor & \multicolumn{1}{|c|}{ Escolaridade } & Fonte de renda própria & \multicolumn{1}{|c|}{ Agressor } & \multicolumn{1}{c|}{ Tempo de relação } \\
\hline Açucena & 48 & Parda & Ens. Médio Incompleto & Não & Companheiro & 15 anos \\
\hline Amarílis & 25 & Branca & Ens. Fundamental Completo & Não & Ex-companheiro & 12 anos \\
\hline Begônia & 35 & Branca & Ens. Médio Incompleto & Não & Ex-companheiro & 2 anos \\
\hline Begônia & 34 & Branca & Ens. Médio Incompleto & Sim & Ex-companheiro & 21 anos \\
\hline Camélia & 54 & Branca & Ens. Superior & Sim & Ex-companheiro & 37 anos \\
\hline Dália & 50 & Branca & Ens. Médio Completo & Não & Companheiro & 32 anos \\
\hline Gérbera & 33 & Parda & Ens. Médio Completo & Sim & Companheiro & 8 anos \\
\hline Girassol & 35 & Branca & Ens. Fundamental Incompleto & Sim & Ex-companheiro & 13 anos \\
\hline Hortênsia & 70 & Branca & Ens. Superior & Sim & Companheiro & 40 anos \\
\hline Magnólia & 55 & Branca & Ens. Fundamental Incompleto & Sim & Ex-companheiro & 24 anos \\
\hline Margarida & 62 & Branca & Ens. Superior & Sim & Companheiro & 13 anos \\
\hline Rosa & 42 & Negra & Ens. Fundamental Completo & Sim & Ex-companheiro & 13 anos \\
\hline Tulipa & 42 & Branca & Ens. Superior & Sim & Companheiro & 26 anos \\
\hline Violeta & 56 & Branca & Ens. Fundamental Incompleto & Sim & Ex-companheiro & 36 anos \\
\hline
\end{tabular}


As experiências das mulheres participantes deste estudo em busca de atenção nas situações de violência são analisadas em duas categorias temáticas, apresentadas a seguir.

\section{Busca de atenção para as situações de violência no setor de Saúde}

Constatou-se que na maioria das trajetórias das mulheres entrevistadas estão presentes serviços e/ou profissionais de saúde. Entre estas, quase todas buscaram atendimentos relacionados à saúde mental, seja com psicólogos, médico psiquiatra ou, quando o acesso ao especialista não era possível, até mesmo com médico de família para tratamento limitado aos psicofármacos. Entre as entrevistadas, metade relatou o uso desse tipo de medicamento.

Eu já sentia a necessidade de procurar um apoio psicológico, psiquiátrico. [...] Foi consultas (com psiquiatra), me deram medicação [...]. (Dália)

Como ele [médico] viu que estava muito abalada, chorando muito, me deu um calmamente fraquinho, ele disse: "vamos começar com a fluoxetina, depois a gente vê como andam as coisas". (Amarílis)

Eu sempre fui muito nervosa, daí para me acalmar um pouco pedi para ela [médica] o remédio [antidepressivo]... (Magnólia)

Esses achados, por um lado, evidenciam a magnitude do sofrimento emocional decorrente das situações de violência. Por outro, reforçam a constatação de que a medicamentalização da violência é a alternativa dominante utilizada por muitos dos(a)s profissionais da saúde que não sabem como proceder diferentemente diante dessas situações. Assim, medica-se para "acalmar" o sofrimento, como se responsabilizasse e silenciasse a vítima para que ela tenha mais força para assumi-lo e suportá-lo individualmente.

Nessa perspectiva, cita-se um estudo que investigou a prescrição de medicamentos com potencial para causar dependência para mulheres que sofreram Violência por Parceiro Íntimo (VPI). Os resultados apontam que as taxas de prescrições eram altas, tanto para analgésicos potencialmente viciantes quanto para depressores do sistema nervoso central. As mulheres que relataram VPI receberam essas prescrições duas a quatro vezes mais frequentemente do que mulheres que não relataram VPI e também são mais propensas a recebê-las de vários (três ou mais) médicos ${ }^{9}$.

Pires $^{10}$ afirma que, comumente, o uso da medicação é considerado essencial por profissionais de saúde para o cuidado das situações avaliadas como demandas de saúde mental. Assim, as situações de violência são exemplo dessa medicamentalização, pois, ao desencadearem sintomas difusos, que dificilmente se enquadram e se resolvem no âmbito dos diagnósticos clássicos biologicistas, com frequência são encaminhadas para a saúde mental como especialidade para receberem prescrição de medicamentos que ajudem a suportar o sofrimento ou a "controlar os ânimos".

É fato que as situações de violência doméstica provocam sofrimento emocional importante, que, muitas vezes, necessita de assistência profissional ${ }^{11}$. Entretanto, questionam-se os processos que transformam esse sofrimento complexo em "doença" que requer quase que unicamente prescrição de medicamentos para seu "tratamento". Não se concebe que a violência seja passível de tratamento no âmbito da clínica exclusivamente. O caráter complexo desses eventos também não se limita ao âmbito das práticas disciplinares e à unicidade de abordagem institucional.

Pode-se analisar que essa medicalização é oriunda das "impropriedades diagnósticas" da violência de que trata Leal ${ }^{12}$. Segundo a autora, mesmo diante de situações que não são patológicas, os(a)s profissionais buscam legitimar suas práticas, na perspectiva biologicista, a partir de sinais e sintomas clínicos, direcionando o atendimento para a oferta existente na clínica biomédica. Assim, muitas vezes, as prescrições se colocam como única alternativa para "tratar" desse sofrimento. Essa análise pode ser acrescida pelo que se entende como oferta de práticas no âmbito dos serviços de saúde, ou seja, o "cardápio diagnóstico" baseado na panaceia médica e farmacológica. 
A medicalização como única possibilidade de ação também é consequência dos processos de aprendizado na formação profissional. Conforme refere Bonfim ${ }^{13}$, há um predomínio da racionalidade biomédica entre os currículos pedagógicos na área da saúde; assim, prepondera um olhar reducionista ao pensar o ser humano sob a perspectiva organicista e focada na doença. A autora conclui que se torna difícil, nessa racionalidade dominante abordar a temática da violência, enquanto um fenômeno complexo, multicausal e que requer a compreensão de concepções ampliadas de saúde.

A avaliação que as mulheres entrevistadas fazem dos atendimentos recebidos no setor da Saúde está condicionada a cada experiência. Em geral, elas afirmaram que o atendimento foi satisfatório; porém, a maioria relatou que não se sentiu bem acolhida pelos profissionais de saúde. $O$ acolhimento, entende-se, implicaria em responsabilização e comprometimento, ou seja, dar seguimento à busca de solução e efetivamente oferecer sustentação institucional.

Eu cheguei no posto de saúde com uma enfermeira e perguntei assim: "eu tenho como marcar um clínico geral? Tem como marcar psicóloga? Eu preciso de ajuda". E elas falaram assim para mim: "no SUS tu não vai conseguir. Pelo SUS tu não consegue psicóloga nenhuma, nem psiquiatra, nem nada". (Açucena)

Ele [o médico] podia ter me ensinado o caminho que eu podia ir, o que eu deveria de fazer, ficar me orientando mais, me cuidando mais, marcando mais pra frente, me cuidando como eu ia ficar, não me largar de mão, só me dá uma receita e me mandar embora. (Amarílis)

Sim, sabiam [da situação de violência], mas eu acho que eles [profissionais do serviço de saúde] atendem muita gente, eu acho que eles não se interessam muito... (Violeta)

Os relatos apresentados pelas participantes deste estudo, muitas vezes, atestaram serviços isolados, estruturas despreparadas e atendimentos desqualificados profissionalmente para atender as mulheres em situações de violência. É frequente o descaso, a negligência e a naturalização da violência doméstica nos atendimentos, atitudes que, muitas vezes, significam fuga do enfrentamento. Identificam-se profissionais sem tempo para se dedicarem a esse tipo de demanda, com encaminhamentos desresponsabilizados quando se esperaria envolvimento.

Em pesquisa com profissionais da saúde, Kiss e Schraiber ${ }^{14}$ identificaram que, apesar de ser considerada um problema relevante pelo(a)s profissionais, a violência está situada fora dos escopos de intervenções profissionais. Para as autoras, as dificuldades na aceitação de casos de violência englobam a estreita definição da competência profissional, com foco biologista; a indefinição tecnológica do fazer profissional, que não consegue incluir o sofrimento que ultrapassa a dimensão fisiopatológica; e a ausência de apoios efetivos em seus serviços.

Trazendo para a discussão as ideias de Raynaut $^{8}$ sobre as dimensões materiais e imateriais da ação humana, percebe-se que o setor saúde atende, no limite, à dimensão material da violência, no que se refere ao biológico, às lesões físicas, aos sintomas clínicos de ansiedade e à depressão. Mas falha no que se refere à atenção à dimensão imaterial, ao subjetivo, ao sofrimento e às relações interpessoais.

Uma das participantes disse "ter sorte" por ter um bom vínculo com as profissionais de saúde da unidade à qual ela é adscrita, evidenciando que o vínculo pode ser "algo raro" para a maioria das pessoas usuárias desses serviços. O vínculo e a escuta qualificada são exemplos de práticas de cuidado, ou tecnologias relacionais, que podem atender a dimensão imaterial da violência como fonte de sofrimento com muita eficiência.

Observou-se que mesmo os aspectos biológicos das consequências da violência, que recebe resposta mais eficiente no setor saúde, como o atendimento em traumatologia, por exemplo, nem sempre são compreendidos ou aceitos pelas mulheres como possibilidade eficaz e suficiente de cuidado. Assim, chamam a atenção as situações em que as mulheres não buscaram ajuda em serviço de saúde, embora houvesse lesões físicas decorrentes da violência. 
Teve vezes eu fiquei bem machucada mesmo, mas eu não procurei [serviço de saúde] por vergonha. (Rosa)

Eu nunca fui tratar, mas essa cicatriz que eu tenho aqui foi uma cabeçada que ele me deu, que eu tratei em casa, ficou aberto. (Gérbera)

Houve também algumas situações que necessitaram de atendimento de saúde, mas as mulheres preferiram esconder a origem das lesões.

Porque essa do tiro foi a maior desculpa que eu dei, eu disse que eu tinha me pisado com a arma dele. Aí o doutor achou que eu estava mentindo, "ah tu está escondendo", "não, é que eu fui mexer e a arma estava carregada e me machucou". (Hortênsia)

Eu fui [ao serviço de saúde] na vez que ele me bateu, mas eu não falei que ele tinha me batido, eu falei que eu tinha caído. (Begônia)

Como motivo para não buscar ajuda nos serviços de saúde ou para esconder as situações de violência, algumas mulheres citaram a vergonha, o medo da recriminação e até mesmo a falta de conhecimento sobre essa possibilidade. Desse modo, a vergonha (recriminação) por terem apanhado e a ilegitimidade da queixa em razão disso contribuem para o isolamento.

Porque... ah, sei lá... as pessoas sempre te recriminam, né, "poxa tu apanhou, mas continua com ele". (Gardênia)

Nunca [procurei ajuda], porque eu não sabia que existia. Eu achava que era só no caso de violência física. (Margarida)

Os motivos relatados estão de acordo com outros estudos, como o de Terra et al. ${ }^{15}$, que buscaram analisar de que modo os sentimentos de medo e vergonha associados às situações de violência impactam as possibilidades de superação da violência doméstica de gênero. As autoras identificaram que o sentimento de vergonha dificulta o diálogo, aumenta o isolamento e a culpa das mulheres que se sentem malvistas, "responsáveis" pelo sofrido e, portanto, obrigadas a aguentarem tais situações ou a resolverem o problema sozinhas. Da mesma forma, o medo pode imobilizar as ações das mulheres em situação de violência, impactando o acesso aos apoios da rede.

A origem desses sentimentos, além dos fatores intrínsecos de cada mulher, também pode ser decorrente do próprio comportamento dos profissionais diante dessas situações, que, não raro, culpabilizam e responsabilizam as mulheres pela situação de violência ${ }^{12,16}$. Desse modo, as mulheres que sentem que não são acolhidas com respeito nos serviços terão mais resistência em procurá-los por medo da repreensão que as revitimiza.

Corroborando esses argumentos e indo além, Villela et al. ${ }^{17}$ consideram que a estrutura física dos serviços de saúde que não proporciona privacidade e a ausência de fluxos definidos para as situações de violência são fatores que dificultam a confissão de vivências íntimas, tornando constrangedora a busca pelo atendimento. Por outro lado, mesmo quando há o relato da violência, muitos profissionais tendem a crer que esse tipo de atendimento deve ser realizado apenas em serviços específicos para essas situações, seguindo a lógica do modelo fragmentado da especialização.

Observa-se, assim, que a invisibilidade da violência nos serviços de saúde e a ausência de ações para essas situações explicam porque muitas mulheres sequer pensam no setor Saúde como um ponto de apoio para superar a situação de violência. As usuárias demandam aos serviços somente o que aprenderam que está disponível na oferta. Conforme $\mathrm{Luz}^{18}$, esse comportamento é consequência da influência do senso comum douto sobre o senso comum, a partir da qual as representações sobre corpo, saúde, doença e tratamento são compartilhadas por profissionais e usuários nos sistemas de Saúde. Sendo assim, no caso das mulheres deste estudo, quando uma delas diz compreender que 
poderia buscar ajuda no serviço apenas no caso de violência física, reflete a representação biologizada ou medicalizada, no sentido do dano orgânico, do que é possível receber como atendimento nos serviços de saúde.

Retomando as reflexões sobre as dimensões materiais e imateriais da violência contra as mulheres (VCM), a partir dos conceitos de Raynaut ${ }^{8}$, ainda que para o autor essas dimensões sejam interrelacionais, formando uma realidade híbrida no que se refere às práticas de saúde, essas dimensões ainda se apresentam amplamente dicotomizadas. Dessa forma, analisa-se que no setor saúde as práticas empregadas nas situações de violências podem ser sintetizadas conforme ilustrado na Figura 1.

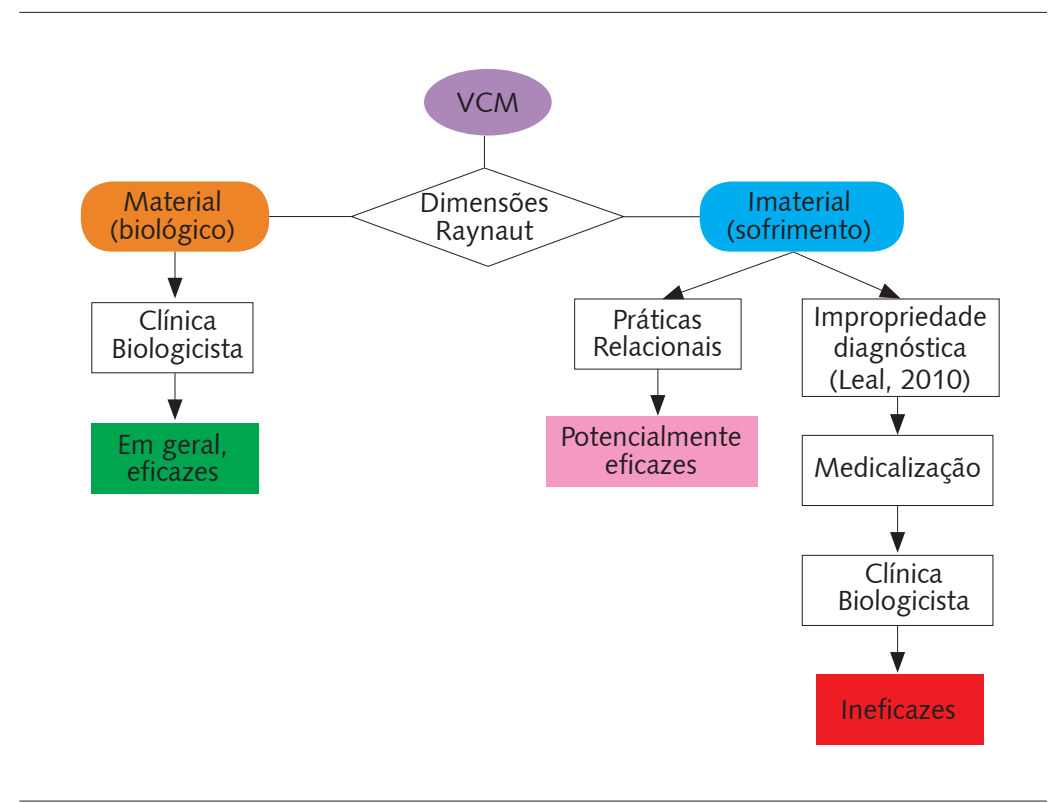

Figura 1. Dimensões materiais e imateriais da VCM a partir dos conceitos de Raynaut.

No que se refere à dimensão material, em geral as práticas biomédicas se mostram eficazes para "tratar" as lesões físicas decorrentes, exceto quando há impedimentos anteriores ao acesso ao serviço de saúde, como o medo e a vergonha revelados pelas mulheres. Porém, no que se refere à dimensão imaterial, duas possibilidades se apresentam. Uma delas diz respeito às práticas relacionais (acolhimento, escuta ativa e vínculo), que, acredita-se, são potencialmente eficazes para lidar com o sofrimento decorrente da violência, mas que ainda são pouco utilizadas pelos profissionais. A outra possibilidade, que aparece como sendo a mais comum, está relacionada à Impropriedade Diagnóstica ${ }^{12}$ diante das situações de violência, levando a ações medicalizantes por parte dos profissionais, que instituem práticas clínicas biomédicas para essas situações, como é o exemplo da prescrição de psicofármacos (a medicamentalização), e que se mostram, invariavelmente, ineficazes isoladamente. Essa forma de olhar para a violência consolida a clássica classificação diagnóstica também dominada pelo senso comum que associa fragilidade de gênero (para as mulheres, é claro) como "doença dos nervos". Essa "doença feminina", entendida como uma fragilidade para enfrentar problemas, marca o descaso e/ou a negligência no campo da atenção profissional e dos serviços de modo geral. 


\section{Busca de atenção para as situações de violência na rede intersetorial}

No que se refere às experiências em busca de atenção nos demais setores da rede, observou-se que o setor policial foi o que mais apresentou reclamações por parte das entrevistadas. As mulheres se queixaram do atendimento negligente e desrespeitoso prestado pelos trabalhadores das delegacias.

E eu vou dizer pra ti que a delegacia não me deu o apoio que eu precisava. [...] não sei se eu voltaria lá. (Açucena)

Acho que elas precisam ter mais tato para lidar, quem sabe uma psicóloga no momento ali [...] do jeito que ela chega, deveria ter um amparo. (Dália)

Em estudo com profissionais de serviços que prestam atendimentos a mulheres em situação de violência, Kiss et al. ${ }^{14}$ identificaram aspectos reducionistas nos atendimentos da esfera policial. Em geral, o objetivo da escuta dos relatos nas delegacias é recolher as informações necessárias à continuidade da trajetória legal; portanto, o relato considerado importante é o que diz respeito aos fatos concretos. Essa atitude impõe limites à interação com as usuárias, pois os componentes da narrativa da mulher que não se encaixam nos artigos previstos na lei não são considerados nas possibilidades de solução para o caso, nem mesmo como objeto de encaminhamentos.

Em sintonia com essas constatações, Villela et al. ${ }^{17}$ ponderam que a instituição policial tem foco no combate à violação das leis, em uma estrutura operacional e cultural que nem sempre consegue lidar com problemas da ordem dos relacionamentos humanos, considerados mais complexos. Além disso, muitas vezes o comportamento dos policiais frente a essas situações, atravessados por concepções estereotipadas sobre os papéis de gênero, reforça a experiência emocional de vulnerabilidade nas mulheres agredidas, criando um círculo vicioso entre violência interpessoal e violência institucional. Sendo assim, os serviços não conseguem cumprir a sua capacidade de interromper a cadeia de produção de violência.

As mulheres entrevistadas também lamentaram a pouca eficácia da Medida Protetiva de Urgência (MPU).

Essa medida, eles não dão segurança 24 horas, se ele quiser chegar e me matar na rua, eu não tenho proteção nenhuma. (Magnólia)

Eu acredito que um papel só de medida protetiva isso não comprova nada, acho que a mulher deveria ser mais protegida em tudo, a brigada levar, a brigada buscar, tirar do local, levar para um ambiente, ajudar mesmo. (Amarílis)

Eu pensava assim: "que proteção eu vou ter?". Até ligar pra brigada, até chamar a brigada, ele já me matou. (Girassol)

As medidas protetivas estão previstas na Lei Maria da Penha e incluem ações como: suspensão da posse ou restrição do porte de armas do agressor; afastamento do agressor do lar, domicílio ou local de convivência com a ofendida; proibição do agressor de aproximação da ofendida, de seus familiares e das testemunhas, fixando o limite mínimo de distância entre estes e o agressor; proibição de contato do agressor com a ofendida, seus familiares e testemunhas por qualquer meio de comunicação; entre outras ${ }^{2}$.

Mesmo com os avanços notórios que a Lei trouxe para a proteção das mulheres, não se pode desconsiderar que o medo manifestado por elas têm razão de ser, em certa medida. Esse "papel", conforme uma delas declara ao documento da MPU, as protege se elas conseguirem acionar a polícia a tempo, o que nem sempre é possível. Questiona-se também até que ponto a ameaça de ser preso realmente impediria um homem, que já decidiu agredir, ou até mesmo matar, a mulher, de fazê-lo. 
No setor Judiciário - representado pelos fóruns, Juizados de Violência Doméstica e Familiar (JVDF), Defensoria Pública Estadual e advogados particulares, embora os atendimentos e o andamento dos processos tenham sido favoráveis para a maioria das mulheres, perceberam-se algumas confusões causadas pela dificuldade na compreensão das informações.

Ela [juíza] só disse que era para cumprir o mandato de medida protetiva e eu não falei nada, eu não disse nada. E acabou a audiência, eu não entendi aquela audiência. [...] Eu não conseguia entender e não falei nada. (Tulipa)

Essa juíza pegar, naquele momento difícil: "então a senhora assine aqui, porque se a senhora vai viver com ele, não precisa processar ele". Ela não me botou um revólver na cabeça, uma faca nos peitos, que nem a gente diz, mas eu fui induzida. (Dália)

Entende-se que essas dificuldades são compreensíveis, levando-se em conta que termos e trâmites jurídicos são difíceis de entender para a maioria das pessoas, e ao se considerar as pessoas com pouca escolaridade ou que estão passando por situações de crise, essa dificuldade acaba sendo potencializada. Todavia, pondera-se que é de responsabilidade do profissional garantir os esclarecimentos das pessoas a quem prestam serviços. Essa negligência institucional produz revitimização.

Em geral, os fluxos entre o setor policial e o judiciário ocorrem conforme o exposto a seguir. Após a denúncia efetuada na Delegacia Especializada de Atendimento à Mulher (Deam), é aberto um processo e enviado ao Ministério Público, para o qual é designado um defensor público para acompanhar as mulheres que não têm recursos. Os processos são agendados para audiência pública no JVDF. Nas audiências, as mulheres são indagadas se querem manter a denúncia, reconciliar ou separar. Muitas vezes, elas são levadas a tomar decisões rapidamente, havendo uma pressão para que reconsiderem a queixa e retornem ao domicílio. Na mediação efetuada no JVDF, os agressores são encaminhados a serviços que oferecem atendimento para problemas, entre os quais encontram-se alcoolismo, uso de drogas, depressão ou agressão ${ }^{19}$.

Conforme referido por Meneghel et al. ${ }^{19}$, a Lei Maria da Penha trouxe aspectos positivos e inovadores, ampliando o acesso das mulheres ao judiciário e garantindo o seu direito de cidadania. Exemplos são o incentivo à criação de Juizados Especiais para a Violência Doméstica e a garantia, expressa na Lei, do atendimento da mulher pela defensoria pública. Contudo, assinalam-se também as fragilidades na sua implementação, como a ineficiência na aplicação das medidas protetivas, a falta de recursos materiais e pessoais para a efetividade das ações previstas, a fragmentação da rede de atenção e o movimento de setores conservadores da sociedade, inclusive entre os magistrados, que atuam para deslegitimar a Lei.

Em relação ao Centro de Referência de Atendimento à Mulher (Cram), ponto central nas trajetórias das participantes deste estudo, esse serviço foi avaliado positivamente de forma unânime por elas. Pode-se considerar que essa seja uma consequência, ou um viés, pelo fato de que as participantes do estudo tinham a adesão ao serviço já estabelecida. Contudo, entende-se que são relevantes as razões que as levam a considerar o Cram um serviço eficiente. As mulheres fazem destaque, por exemplo, para o acolhimento e para as orientações recebidas.

Aqui eu senti um respaldo, aquele amparo, aquele acolhido. (Dália)

[...] porque aqui eles atendem a gente melhor, entendem a gente melhor, e resolve a situação também... (Rosa)

Essa recepção que eu estou tendo aqui no Cram, que eu não conhecia. Aqui eles estão me fazendo eu me sentir mais humana, sentir gente, sabe? Mostraram que eu posso seguir em frente mesmo tendo quatro filhos, que eu não preciso dessa pessoa do meu lado. (Gérbera) 
Fica evidente nos relatos a importância que as mulheres dão aos aspectos relacionais nos atendimentos da equipe do Cram. Referiram, muitas vezes, o espaço para diálogo, a paciência para fornecer explicações, a confiança e o vínculo estabelecido com os profissionais.

Destaca-se que o Cram, ao exercer papel de articulador da rede de atenção às mulheres em situação de violência, é capaz de suprir muitas lacunas deixadas pelos outros serviços, como a incompreensão sobre os fluxos de atendimento nos diferentes setores. Ao explicar os procedimentos da rede intersetorial, orientar e esclarecer, a equipe presta apoio fundamental a essas mulheres, marcando positivamente suas trajetórias. Um exemplo importante é a elaboração do Plano de Segurança Pessoal nos atendimentos realizados pela equipe do Cram. Por meio desse planejamento, o(a)s profissionais buscam esclarecer a mulher sobre a real finalidade e potencialidades da MPU e estabelecer junto com ela algumas ações de prevenção para a sua proteção.

Outros serviços da rede, como conselho tutelar, escola, serviços de assistência social e casasabrigo, aparecem em menor frequência nos relatos das participantes deste estudo, mas não são menos importantes. Um exemplo é a trajetória de Rosa, que teve início após o seu filho ter relatado na escola a situação de violência que ela vivenciava. A partir disso, a escola a chamou para conversar e a encaminhou para serviços de referência no atendimento às mulheres vítimas de violência. Outros exemplos estão nas falas a seguir.

O Conselho Tutelar eu gostei muito, fui muito bem atendida. Todas as vezes que eu fui lá eles se preocuparam muito comigo e com os meus filhos. (Amarílis)

Eu acredito que as casas de abrigo são boas, hoje eu vejo com outros olhos de quando eu não conhecia, eu achava que seria "ah, um abrigo, meu deus, né, é horrível". Muito pelo contrário, eles me protegem o tempo todo [...]. (Amarílis)

Percebeu-se que muitos desses serviços foram pontos de apoio significativos para as mulheres, sendo, algumas vezes, impulsionadores das trajetórias em busca de atenção.

Considerando a necessária articulação da rede de atenção, destaca-se que a Lei Maria da Penha promoveu melhorias nos campos da prevenção da violência, especialmente em razão da maior visibilidade social do fenômeno. As repercussões incluem mudanças positivas na assistência a mulheres e na punição aos agressores, devido à ampliação do acesso aos serviços e da divulgação dos direitos das mulheres em situação de violência. Entretanto, ainda existem obstáculos a serem superados para o fortalecimento das medidas preconizadas por essa Lei, os quais incluem maior investimento na qualificação dos profissionais e a instituição de ações articuladas entre os locais de atendimento ${ }^{20}$.

\section{Considerações finais}

Em relação às experiências das mulheres entrevistadas neste estudo em busca de atenção nas situações de violência, é preciso ponderar que o fato de a pesquisa ter sido realizada em um serviço relevante e central da rede de atenção às mulheres em situação de violência no município do estudo marca essa passagem e faz com que as trajetórias das participantes tenham elementos e fluxos muito semelhantes em sua sequência. Sabe-se que esse padrão não pode ser generalizado para todas as mulheres em situação de violência, sendo esse um viés das opções realizadas neste estudo. Contudo, pode-se evidenciar, a partir das experiências relatadas pelas participantes, elementos que interferem na trajetória das mulheres em busca de ajuda.

No que se refere ao setor Saúde, destaca-se a demanda por atenção à saúde mental, decorrente do sofrimento causado pelas situações de violência, a invisibilidade dessas situações no serviço e também a predominância de práticas medicalizadas. Nos demais serviços da rede intersetorial, também foram relatadas inadequações das práticas profissionais e da organização e estrutura de muitos serviços para acolher essas mulheres. Todavia, foram observados fatores que contribuem para a superação das violências, expressos nas situações em que as mulheres se depararam com atendimentos qualificados 
nos serviços da rede, nos quais prevaleceu o acolhimento, o esclarecimento das dúvidas e as respostas satisfatórias das ações realizadas.

Diante dessas constatações, evidencia-se que tão importante quanto dar resposta às questões objetivas (materiais) da violência - as lesões físicas, os danos patrimoniais, a garantia dos direitos e da segurança -, faz-se necessário também oferecer apoio às questões subjetivas (imateriais): o sofrimento decorrente de uma mistura complexa de sentimentos (amor, ódio, raiva, ansiedade, medo, vergonha, culpa, compaixão e tantos outros). Sendo assim, considera-se imprescindível superar a negligência no campo da atenção profissional, com o estabelecimento de práticas pautadas pela integralidade da atenção, pela responsabilização e pelo comprometimento. Essa difícil proposta de enfrentamento, acredita-se, só é possível a partir de uma atuação qualificada e profundamente articulada da rede de serviços e desmedicalizada no setor Saúde.

\section{Colaboradores}

Joannie dos Santos Fachinelli Soares realizou a coleta de dados. Joannie dos Santos Fachinelli Soares e Marta Julia Marques Lopes participaram ativamente na discussão dos resultados, assim como da revisão e na aprovação da versão final do trabalho.

\section{Referências}

1. Schraiber LB, D'Oliveira AFPL, Falcão MTC, Figueiredo WS. Violência dói e não é direito: a violência contra a mulher, a saúde e os direitos humanos. São Paulo: Editora UNESP; 2005.

2. Presidência da República (BR). Lei no 11.340, de 7 de Agosto de 2006. Cria mecanismos para coibir a violência doméstica e familiar contra a mulher. Diário Oficial da União. 8 Ago 2006.

3. Menezes PRM, Lima IS, Correia CM, Souza SS, Erdmann AL, Gomes NP. Enfrentamento da violência contra a mulher: articulação intersetorial e atenção integral. Saude Soc. 2014; 23(3):778-86.

4. Cripe $S M$, Espinoza $D$, Rondon $M B$, Jimenez $M L$, Sanchez $E$, Ojeda N, et al. Preferences for intervention among Peruvian women in intimate partner violence relationships. Hisp Health Care Int. 2015; 13(1):27-37.

5. Costa MC, Lopes MJM. Elementos de integralidade nas práticas profissionais de saúde a mulheres rurais vítimas de violência. Rev Esc Enferm USP. 2012; 46(5):1088-95.

6. Minayo MCS. O desafio do conhecimento: pesquisa qualitativa em saúde. 12a ed. São Paulo: Hucitec; 2010.

7. Bardin L. Análise de conteúdo. São Paulo: Edições 70; 2011.

8. Raynaut C. Interdisciplinaridade: mundo contemporâneo, complexidade e desafios à produção e à aplicação de conhecimentos. In: Philippi Jr. A, Silva Neto A, editores. Interdisciplinaridade em ciência, tecnologia e inovação. Barueri: Manole; 2011. p. 69-105.

9. Stene LE, Dyb G, Tverdal A, Jacobsen GW, Schei B. Intimate partner violence and prescription of potentially addictive drugs: prospective cohort study of women in the Oslo Health Study. BMJ Open [Internet]. 2012 [citado 26 Nov 2015]; 2(2):e000614. Disponível em: http://bmjopen.bmj.com/content/2/2/e000614.full.

10. Pires ML. Entre a estratégia saúde da família e o núcleo de apoio à saúde da família: o que se nomeia demanda de saúde mental? [dissertação]. Porto Alegre (RS): Universidade Federal do Rio Grande do Sul; 2014. 
11. Hink AB, Toschlog E, Waibel B, Bard M. Risks go beyond the violence: association between intimate partner violence, mental illness, and substance abuse among females admitted to a rural Level I trauma center. J Trauma Acute Care Surg. 2015; 79(5):709-14.

12. Leal SMC. "Lugares de (não) ver?" As representações sociais da violência contra a mulher na atenção básica de saúde [tese]. Porto Alegre (RS): Universidade Federal do Rio Grande do Sul; 2010.

13. Bonfim EG. A temática da violência na formação da enfermagem: racionalidades hegemônicas e o ensino na graduação [tese]. Porto Alegre (RS): Universidade Federal do Rio Grande do Sul; 2015.

14. Kiss LB, Schraiber LB, D'oliveira AFPL. Possibilidades de uma rede intersetorial de atendimento a mulheres em situação de violência. Interface (Botucatu). 2007; 11(23):485501.

15. Terra MF, D' Oliveira AFPL, Schraiber LB. Medo e vergonha como barreiras para superar a violência doméstica de gênero. Athenea Digital [Internet]. 2015 [citado 11 Set 2016]; 15(3):109-25. Disponível em: http://atheneadigital.net/article/view/v15-n3-terradoliveira-schraiber.

16. Costa MC. Violência contra mulheres rurais, agendas públicas municipais e práticas profissionais de saúde: o visível e o invisível na inconsciência do óbvio [tese]. Porto Alegre (RS): Universidade Federal do Rio Grande do Sul; 2012.

17. Villela WV, Vianna LAC, Lima LFP, Sala DCP, Vieira TF, Vieira ML, et al. Ambiguidades e contradições no atendimento de mulheres que sofrem violência. Saude Soc. 2011; 20(1):113-23.

18. Luz MT. Comparação de representações de corpo, saúde, doença e tratamento em pacientes e terapeutas de homeopatia, acupuntura e biomedicina da rede de saúde do munícipio do Rio de Janeiro. In: Luz MT, Barros NF, organizadores. Racionalidades médicas e práticas integrativas em saúde: estudos teóricos e empíricos. Rio de Janeiro: UERJ/IMS/ LAPPIS; 2012. p. 217-47.

19. Meneghel SN, Mueller B, Collaziol ME, Quadros MM. Repercussões da Lei Maria da Penha no enfrentamento da violência de gênero. Cienc Saude Colet. 2013; 18(3):691-700.

20. Alves ES, Oliveira DLLC, Maffacciolli R. Repercussões da Lei Maria da Penha no enfrentamento da violência doméstica em Porto Alegre. Rev Gauch Enferm. 2012; 33(3):141-47.

Soares JSF, Lopes MJM. Experiencias de mujeres en situación de violencia en búsqueda de atención en el sector salud y en la red intersectorial. Interface (Botucatu). 2018; 22(66):789-800.

El objetivo del estudio fue analizar las experiencias de mujeres en situación de violencia en búsqueda de atención en la salud y en la red intersectorial. Se utilizó un abordaje cualitativo. Las participantes fueron 14 mujeres atendidas en un Centro de Referencia de Atención a la Mujer debido a situaciones de violencia en las relaciones íntimas. Se realizaron entrevistas en profundidad e investigación documental en los formularios de atención. El análisis de contenido constató inadecuación de las prácticas profesionales y de la organización y estructura de muchos servicios para acoger a esas mujeres. Se destaca la necesidad de establecer una adecuada articulación de la red intersectorial para poder atender tanto los daños físicos y la garantía de los derechos y de la seguridad, como para ofrecer apoyo al sufrimiento consecuente.

Palabras clave: Violencia contra la mujer. Atención de la salud. Intersectorialidad.

Submetido em 24/09/17. Aprovado em 22/02/18. 